\section{Dosimetry and Radioenhancement Comparison of Gold Nanoparticles in Kilovoltage and Megavoltage Radiotherapy using MAGAT Polymer Gel Dosimeter}

\author{
Farahani S. ${ }^{1,2}$, Riyahi Alam N. ${ }^{*}$, Haghgoo S. ${ }^{3}$, Khoobi M.4,5, \\ Geraily Gh. ${ }^{1}$, Gorji E. ${ }^{3}$
}

\begin{abstract}
Background: Numerous unique characteristics of the nanosized gold, including high atomic number, low toxicity, and high biocompatibility make it one of the most appropriate nanostructures to boost radiotherapy efficacy. Many in-vivo and in-vitro investigations have indicated that gold nanoparticles (AuNPs) can significantly increase tumor injuries in low kilovoltage radiotherapy. While deep-lying tumors require much higher energy levels with greater penetration power, and investigations carried out in megavoltage energy range show contradictory results.
\end{abstract}

Objective: In this study, we quantitatively assess and compare dose enhancement factors (DEFs) obtained through AuNPs under radiation of Cobalt-60 source $(1.25 \mathrm{MeV})$ versus Iridium-192 source $(380 \mathrm{KeV})$ using MAGAT gel dosimeter.

Material and Methods: MAGAT polymer gel in both pure and combined with $0.2 \mathrm{mM}$ AuNPs was synthesized. In order to quantify the effect of energy on DEF, irradiation was carried out by Co-60 external radiotherapy and Ir-192 internal radiotherapy. Finally, readings of irradiated and non-irradiated gels were performed by MR imaging.

Results: The radiation-induced R2 (1/T2) changes of the gel tubes doped with AuNPs compared to control samples, upon irradiation of beams released by Ir-192 source showed a significant dose enhancement $(15.31 \% \pm 0.30)$ relative to the Co-60 external radiotherapy $(5.85 \% \pm 0.14)$.

Conclusion: This preliminary study suggests the feasibility of using AuNPs in radiation therapy (RT), especially in low-energy sources of brachytherapy. In addition, MAGAT polymer gel, as a powerful dosimeter, could be used for 3D visualization of radiation dose distribution of AuNPs in radiotherapy.

\section{Keywords}

Brachytherapy, Dose Enhancer, External Radiotherapy, Gel Dosimetry, Nanotechnology

\section{Introduction}

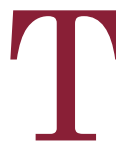
reatment of cancer, as one of the main causes of death in the world, is a challenges for today's medical knowledge that is limited to radiation therapy (RT), surgery and chemotherapy. RT as a branch of the standard-of-care of cancerous patients is used for almost half of the patients [1]. At the current era, we have been observing a face of RT that is changing and developing quickly to amplify its efficacy.
${ }^{1}$ Department of Medical

Physics and Biomedi-

cal Engineering, Tehran

University of Medical

Sciences, Tehran, Iran

'Students' Scientific

Research Center, Tehran

University of Medical Sci-

ences, Tehran, Iran

${ }^{3}$ Pharmaceutical Depart-

ment, Food \& Drug Labo

ratory Research Center,

Food \& Drug Organiza-

tion (FDO), Tehran, Iran.

${ }^{4}$ Nanobiomaterials

Group, Pharmaceuti-

cal Sciences Research

Center, Tehran University

of Medical Sciences,

Tehran 141761411, Iran

${ }^{5}$ Department of Phar-

maceutical Biomaterials

and Medical Biomateri-

als Research Center,

Faculty of Pharmacy,

Tehran University of

Medical Sciences, Teh-

ran, Iran

*Corresponding author:

N. Riyahi Alam

Department of Medical

Physics and Biomedi-

cal Engineering, Tehran

University of Medical

Sciences, Tehran, Iran

E-mail: riahialam@gmail. com

Received: 30 August 2017

Accepted: 12 December 2017 
However, still the maximum of the dose to the tumoral tissue is delivered while sparing damage to the nearby normal tissues is the greatest weakness of this treatment.

The considerable advances in nanoscience have provided new potential things in cancer diagnosis and therapy [2-4]. High-atomic number (Z) nanoparticles (NPs) cause targeted dose enhancement in tumor tissue. In the presence of high $\mathrm{Z}$ nanoparticles and based on the incident photon energy, photoelectric absorption cross sections will increase. Shortly afterward, the interaction of the short range generated photoelectrons, Auger electrons and ultimately free radicals enhance the death of diseased cells $[5,6]$. Furthermore, with the effective targeting of tumors using NPs based on the effect of the enhanced permeability and retention (EPR), as well as active targeting using molecular ligands, dose enhancement locally can be achieved [7].

The dose enhancement capabilities of high $\mathrm{Z}$ nanomaterials have been anticipated in Monte Carlo calculations, and in vivo and in vitro studies have displayed that NPs such as gadolinium, platinum and gold are proper radio-enhancer in cancer RT [8-14]. The initial Monte Carlo simulation studies were carried out by Cho et al. [9] who predicted the remarkable dose enhancement of tumor caused by gold nanoparticles (AuNPs) (e.g. $>40 \%$ ) using low-energy sources. Following the pioneering work by Herold et al. [15], Hainfeld showed a good radiosensitivity enhancement of AuNPs with $250 \mathrm{kVp} \mathrm{x}$-rays/photons in mouse models [16]. Subsequently, in order to achieve the highest increment in absorbed dose produced by NPs, many studies have investigated the factors affecting dose enhancement factor (DEF) [17-27]. The size and concentration of nanoparticles and incident energy range were found as the main factors influencing DEF.

In terms of the nanoparticle dimensions, two goals must be followed. Firstly, what is the optimum size for the most penetration of NPs into the target tissue? Due to increasing pen- etration and diffusion of NPs in the target site, the deposited dose is also expected to increase. Secondly, how the particle size particularly affects the dose enhancement of target tissue? In response to the first question, depending on the target tissue and the shape and coating of NPs, their size can be different. For example, Chithrani using AuNPs in the sizes 14, 50 and $74 \mathrm{~nm}$ in Hella cells indicated that the cellular uptake of NPs with the diameter of $50 \mathrm{~nm}$ is the highest one $[17,18]$. In contrast, Zhang et al. found that PEG-coated AuNPs with 12.1 and $27.3 \mathrm{~nm}$ diameters revealed the highest uptake and radiosensitization compared to other sizes (4.8 and $46.6 \mathrm{~nm}$ NPs) [19]. It should be noted that by reducing the size of the nanoparticle, its toxicity may increase $[27,28]$. In the study carried out by Fenart et al. that investigating the effect of nanoparticles coating on passing through the blood-brain barrier (BBB) cell model was a purpose, it was found that $60 \mathrm{~nm}$ NPs coated with a lipid bilayer could pass 3 or 4 times more than uncoated particles [20]. In response to the second question, the results of Leung et al. showed that as the diameter of the nanoparticle and the number of secondary electrons increase [21]. Reckoning with these findings and the challenge of choosing a larger size of particle, resulting in a higher dose enhancement and, at the same time, less penetration into the cell, 50nm NPs were used in this study.

The second influential factor on DEF is the optimal concentration of NPs. This factor can be reviewed from two points of view. First, what is the impact of concentration on the cellular uptake? And second, how does specifically this factor affect absorbed dose? In response to the first question, as noted in the context of nanoparticle size, depending on the cellular media and the physical and chemical properties of AuNPs, their penetration can differ [22-25]. The answer to the second question can be referred to the studies by Mesbahi in 2013 and Cho in 2009 [26, 9]. Their simulation studies showed that increasing the num- 
ber of NPs following increasing their concentrations leads to an absorbed dose increment. On the other side, the most important limiting factor is the toxicity of NPs at high concentrations of particles, which varies with the type of nanoparticles. In the case of AuNPs depending on the toxicity assays, the cell type and the physicochemical properties of the particles, the reported cytotoxicity results are different [27]. According to many reports, AuNPs at sizes larger than $\sim 10 \mathrm{~nm}$, and concentrations of 0.5-5 mM are non-toxic [27, 29, 30]. Considering the above studies, $0.2 \mathrm{mM}$ concentration was selected in this study.

The third important factor in DEF is the incident energy range. A significant number of studies have focused on dose enhancement properties of AuNPs during low energy RT $[18,31-32]$. Cell damage caused by photons with the radiation energy in the $20-200 \mathrm{keV}$ range is the most while using this therapy energy is limited to superficial lesions, and so their application in RT is very limited [33]. The findings of the studies carried out in the dose enhancement of NPs exposed to megavoltage beams are contradictory [34, 35]. Acceptable DEFs induced by various NPs under the irradiation of 6oCo $\gamma$-rays, in the investigations of Maggiorella, Sabbaghizadeh, and Deyhimihaghighi were in contradiction with the results of Ezzati, Kakade, and Toossi studies [36-41]. Therefore, in this study, we investigate the potential of $50 \mathrm{~nm}$ AuNPs as radio-enhancer in the decayed energy from the Co-60 source compared with the Ir-192 source, using the MAGAT gel dosimeter.

\section{Material and Methods}

\section{Gel Preparation}

The investigation of the radiosensitizing effect of AuNPs was carried out on the MAGAT polymer gel. A standard gel formulation for MAGAT was employed, as reported previously [42]. Mass concentration of gel ingredients is shown in Table 1. First, Gelatin (porcine skin,
Table 1: Composition of $100 \mathrm{ml}$ of MAGAT gel dosimeter.

\begin{tabular}{cc} 
Component & Mass concentratin \\
\hline Mili-Q Water & $85 \%, 85 \mathrm{ml}$ \\
\hline Gelatin & $6 \%, 6 \mathrm{~g}$ \\
\hline MAA & $9 \%, 9 \mathrm{~g}$ \\
\hline THPC & $10 \mathrm{mM}$
\end{tabular}

Type A, Sigma Aldrich) was added to the half of Milli-Q water at room temperature under magnetic stirring for 30 minutes. After forming a homogeneous solution, the mixture was heated to $50{ }^{\circ} \mathrm{C}$ and then kept at this temperature to obtain a clear solution, approximately 30 minutes. Meanwhile, the Methacrylic acid (MAA, Merck, Germany) and Tetrakis (hydroxymethyl) phosphonium chloride (THPC, Sigma Aldrich) were dissolved in the $30 \%$ and $20 \%$ total water volume, respectively, then were heated to $30{ }^{\circ} \mathrm{C}$. Following cooling the solution down to $35^{\circ} \mathrm{C}$, first MAA solution and then THPC solution were added and the obtained solution was stirred for typically 2 minutes. The gel solution was then separated into two volumes where one container was filled with the pure gel as a control and the other one with the gel that included $0.2 \mathrm{mM}$ AuNPs $(50 \mathrm{~nm}$, Nanomabna Iranian Co, Tehran, Iran) that stirred again continuously without heating for around 5 minutes. Finally, both the pure gel and the gel loaded by AuNPs were quickly poured into the 12-ml cylindrical glass calibration and test tubes. Then all the samples were wrapped by aluminum foil to prevent influence of light and transferred in a refrigerator at about $4{ }^{\circ} \mathrm{C}$ for 24 hours.

\section{Irradiation}

Internal Radiation Therapy Practice

For brachytherapy purposes, a Plexiglas phantom was constructed such that all gelfilled tubes were irradiated simultaneously. The phantom was designed in a shape of a cube size $20 \times 20 \times 20 \mathrm{~cm}^{3}$ with a $1.6 \mathrm{~mm}$ Plexi- 
glas hollow rod at its center to load the Ir-192 source using an interstitial catheter. Due to the dependence of the polymer gel dosimeters on the dose rate [43], the irradiation of test and calibration tubes should be done with the same irradiation source and/or machines. Consequently, in order to calibrate the fabricated gel, the pure gel tubes were simultaneously irradiated by Ir-192 source. The tubes were located vertically in the water-filled phantom at radiuses of $2.25,3.75$ and $5.25 \mathrm{~cm}$ from the loaded source (Figure 1). To increase the precision of the gel dosimetry, twelve tubes of pure gel were irradiated with average doses of 3.17-9 Gy and the average dose of each group were calculated. As shown in Figure 1, tubes with the same letters were fixed at the same distance from the source so that the delivered doses to the center of all four tubes in each group were equal. A gel tube was not irradiated as a control.

Twelve gel-filled tubes with AuNPs were irradiated with an Ir-192 source in the same way as mentioned in the calibration procedure. To determine the relaxation time of AuNPs, one of the samples with AuNPs was not irradiated
(0Gy).

External Radiation Therapy Practice First, to calibrate the fabricated gel, the pure gel tubes were irradiated by the Theratron Co-60 machine, using a $40 \times 40 \times 20$ cm container in which the samples could have been placed horizontally. The calibration gel tubes were irradiated from 0 to $10 \mathrm{~Gy}$ in the waterfilled phantom with the parameters as follows: Field size $=15 \times 15 \mathrm{~cm}^{2}, \mathrm{SSD}=70 \mathrm{~cm}$, and Dose rate $=81 / 92 \mathrm{cGy} / \mathrm{min}$. dose distribution homogenization was achieved by two parallel opposed fields. Irradiation of the samples containing AuNPs was also carried out using the Co-60 machine (1.25 MV) with a uniform dose 2.5 to 10 Gy with the interval of 2.5 as described above (Figure 2). One of the samples containing AuNPs was not irradiated as a control.

\section{MRI Scanning}

One day after irradiation, Magnetic resonance (MR) images were acquired to permit sufficient time for polymerization completion. Also, all the tubes were placed in the MRI scanner room for 5 hours before scanning to achieve a uniform thermal equilibrium [42,

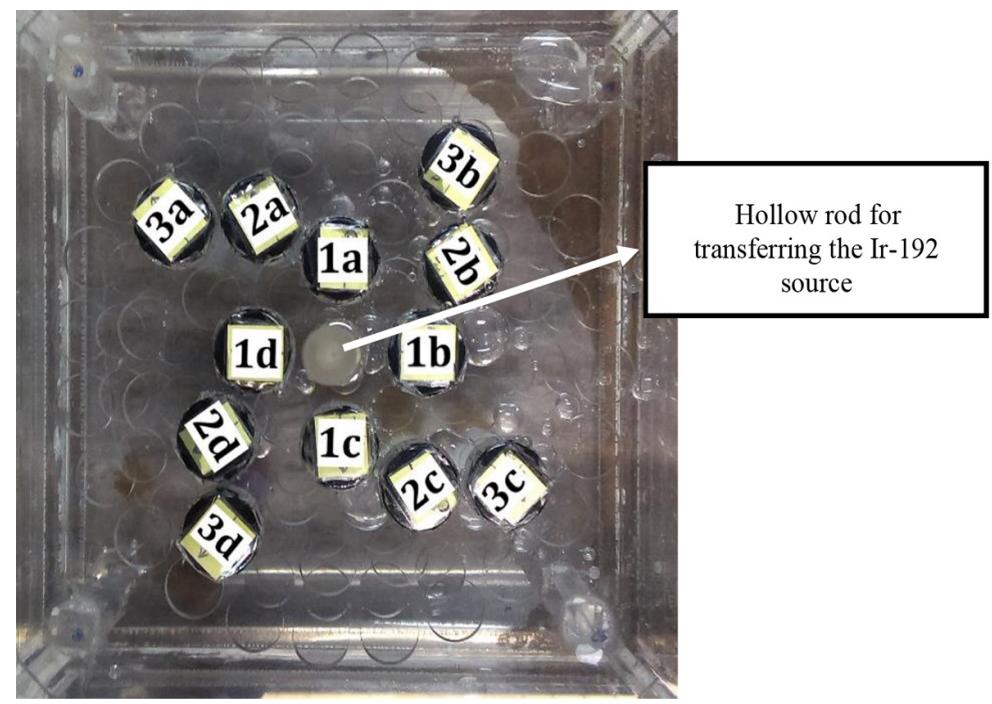

Figure 1: Arrangement of gel containing tubes in brachytherapy phantom. Group 1 tubes with a distance of $2.25 \mathrm{~cm}$ from the source center received the same dose of $9 \mathrm{~Gy}$. Similarly, group 2 tubes, with a $3.75-\mathrm{cm}$ distance of the phantom center received a dose of $4.78 \mathrm{~Gy}$ and group 3 tubes with $5.25-\mathrm{cm}$ distance from the center, were exposed to a dose of $3.01 \mathrm{~Gy}$. 


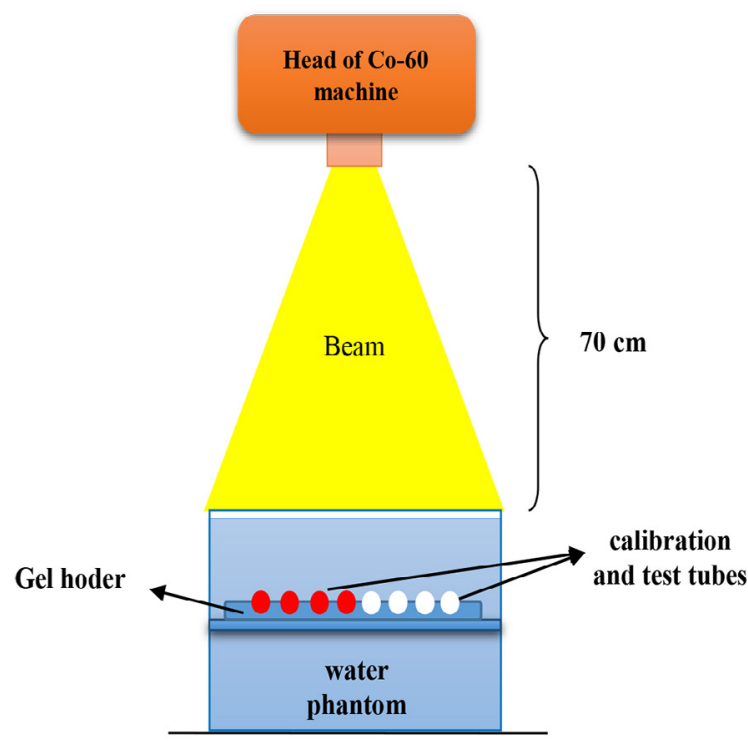

Figure 2: The schematic view of irradiation set up of the calibration and test tubes. All tubes were located perpendicular to the beam direction in a phantom filled with water and were irradiated simultaneously.

44]. Scanning of irradiated and non-irradiated gel tubes was conducted using a $1.5 \mathrm{~T}$ scanner (Siemens, Magneton Vision) in a head coil. The radiation-induced polymerization amount of polymer gel is reflected by a reduction in longitudinal relaxation time (T1) and transverse relaxation time (T2). T2 having a large sensitivity, dynamic range, and signal-to-noise ratio is more efficient than $\mathrm{T} 1[45,46]$. Therefore, a fast-spin echo sequence with 16 echo numbers was used to obtain T2-weighted images based on presented parameters in Table 2 .

\section{Data Analysis}

Image processing was implemented using an R2 map computing program coded in MATLAB (Mathworks Inc). In the program, the R2 calculation was based on the following equation:

$$
\mathbf{S}=\mathbf{S}_{\mathbf{0}} \cdot \mathbf{e}^{-\mathbf{R} 2 \times T E}
$$

Where $\mathrm{S}$ and $\mathrm{S}_{0}$ are the signal intensity related to TE (echo time) and the signal intensity belonging to $\mathrm{TE}=0$, respectively. The selected
Table 2: MR imaging protocol for obtaining T2-weighted images.

\begin{tabular}{ll} 
Scanning parameter & Value \\
\hline TR (repetition time) & $3000 \mathrm{~ms}$ \\
\hline TE( echo time) & $20 \mathrm{~ms}$ \\
\hline ES (Space between echoes) & $20 \mathrm{~ms}$ \\
\hline FOV ( field of view) & $200 \mathrm{~mm}$ \\
\hline Matrix size & $256 \times 256$ \\
\hline NEX (Number of averages) & 2 \\
\hline Slice thickness & $4 \mathrm{~mm}$ \\
\hline Number of slices & $8 \mathrm{slices}$ \\
\hline Gap between slices & $5 \mathrm{~mm}$
\end{tabular}

regions of interest (ROIs) were then drawn for each separate sample in the R2 image. Finally, the mean and standard deviation of selected ROI representative of each gel tube were mapped to known dose for plotting the R2dose response curve. In order to decrease the uncertainties arising from the noise, the experiments were repeated three times in the same condition. Statistical analysis of the obtained data (presented as mean values \pm standard deviation) was determined by the unpaired Student t-test. The significance level of the difference between the control and the experimental groups was defined when the p-value was less than 0.05 .

\section{Results}

MAGAT polymer gel response to $\gamma$-rays released by cobalt and iridium sources was characterized by R2 maps acquired from MR images using Matlab. Calibration curves shown in Figures $3 a$ and $b$ have obtained from mapping R2 values to known doses, which show the acceptable linearity of gel dosimeter over the used dose range in both studied energies.

Figures 4 and 5 provide the R2 maps obtained for control and test tubes irradiated with the Co-60 and Ir-192 sources. According to the figures, the dose enhancement in the presence of AuNPs is clearly evident compared with the control groups, especially in high doses. 
(a)

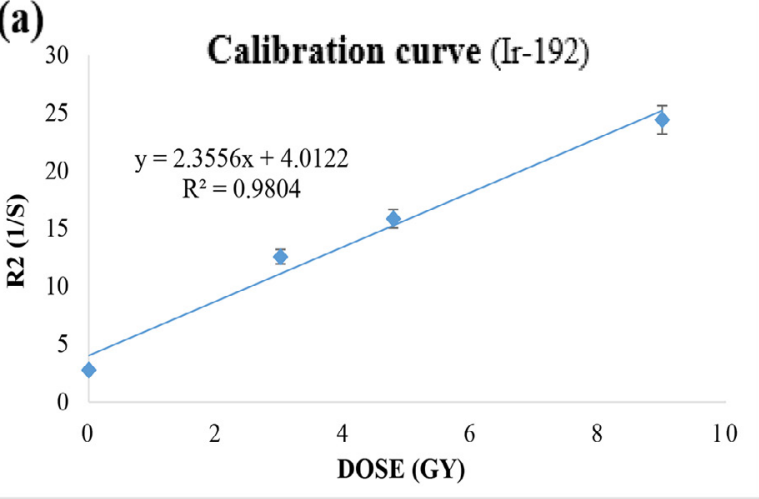

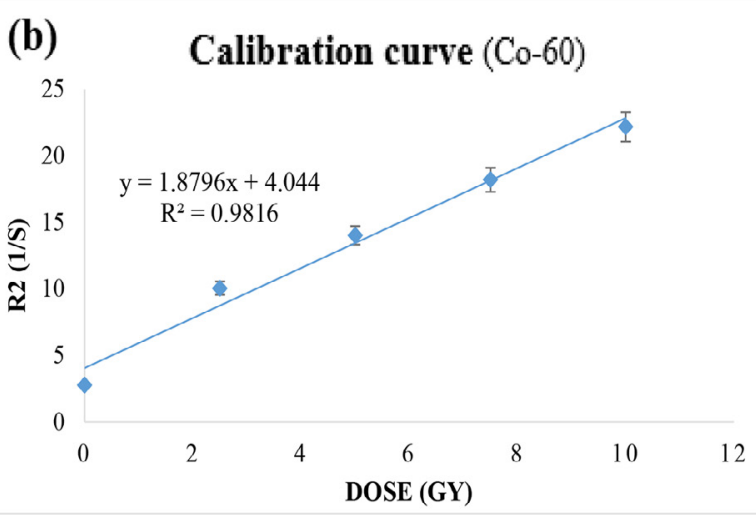

Figure 3: Calibration curves of MAGAT gel dosimeter under irradiation of a) Ir-192 source in the brachytherapy and b) Co-60 source in the external radiation therapy. Both curves show the linear response of the gel dosimeter to the used radiation dose ranges.

As presented in Figures 4 and 5, the R2 values in the gels containing AuNPs decreased when compared with of the gels without NPs at the dose of $0 \mathrm{~Gy}$. Therefore, the R2 values of the AuNPs induced polymerization related to the delivered dose were obtained by adding the difference of R2 values of control gel tubes with and without the NPs to the R2 values of irradiated gel tubes loaded with AuNPs (equation 2).

$\mathbf{R 2}(\text { AuNPs })_{\text {irradiated }}=\mathbf{R 2}(\mathrm{Gel}+\mathrm{AuNPs})_{\text {irradiated }}+\left(\mathbf{R} 2(\mathrm{Gel})_{\text {non-irradiated }}-\mathbf{R} 2(\text { AuNPs })_{\text {non- irradiated }}\right)$

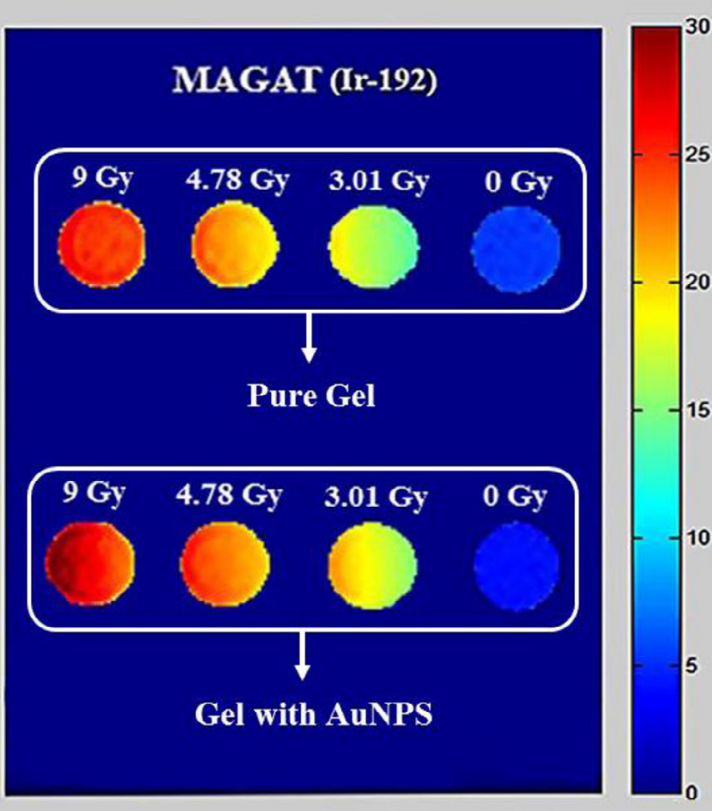

Figure 4: The R2 map of transverse slice belongs to calibration and AuNPs-incorporated gel tubes irradiated by doses of 0-9 Gy given by Iridium-192 source.

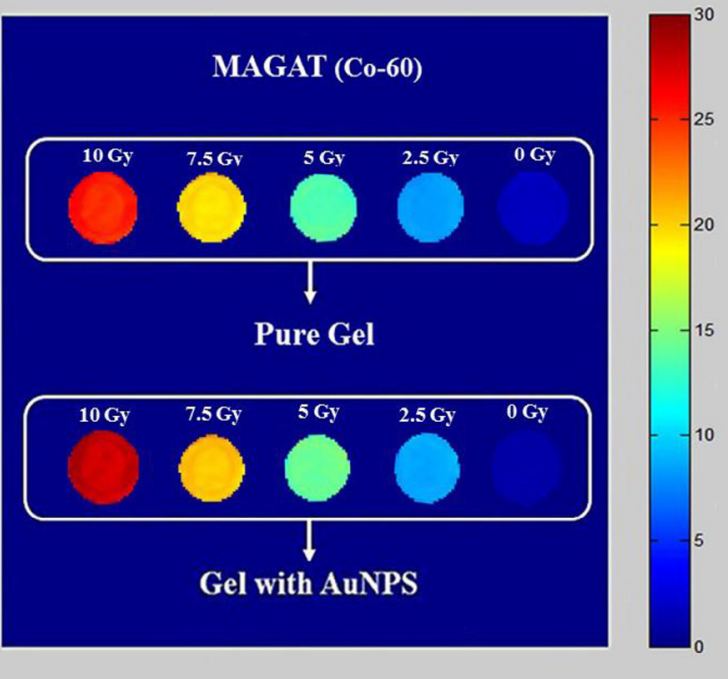

Figure 5: The R2 map acquired from MR images of gel tubes with and without the AuNPs irradiated with doses of 0-10 Gy given by a Cobalt-60 source. 
Eventually, DEF at any region of interest was derived from the ratio between dose at any pixels of the image of the tube doped with AuNPs and the dose in the same point of the tube without AuNPs (control). R2-dose curves derived from the R2 images of the gel tubes using equation 2 have been displayed in Figures 6 and 7. The average value of the DEF calculated for brachytherapy experiment was $15.31 \% \pm 0.30$, which decreased to $5.85 \%$ \pm 0.14 in external radiation therapy. As well as the comparison between the AuNPs induced dose enhancement and radiation dose are tabulated (Table 3). As seen in this table, the DEF values rose by increasing radiation dose in both the external and internal radiotherapy procedures.

\section{Discussion}

The main goal of RT is to deliver the maximum lethal dose to the tumoral tissues while protecting the surrounding healthy tissues. To achieve this goal, many studies have focused on the use of high atomic elements as radiosensitizers. The purpose of this study was to evaluate and compare the dose enhancement factors of AuNPs in the two energies of the Co$60(1.25 \mathrm{MeV})$ and $\mathrm{Ir}-192(380 \mathrm{keV})$ sources

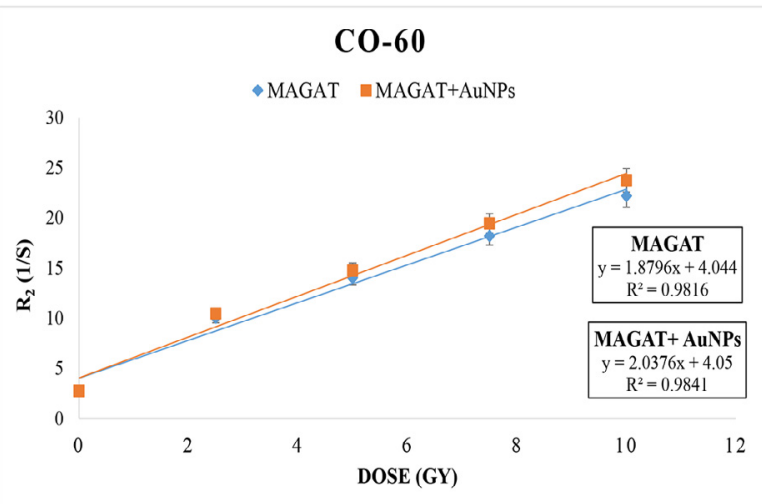

Figure 6: The R2-dose-response curve of AuNPs under Co-60 external radiotherapy compared to control group. Recorded error bars are mean standard deviations for three independent tests.

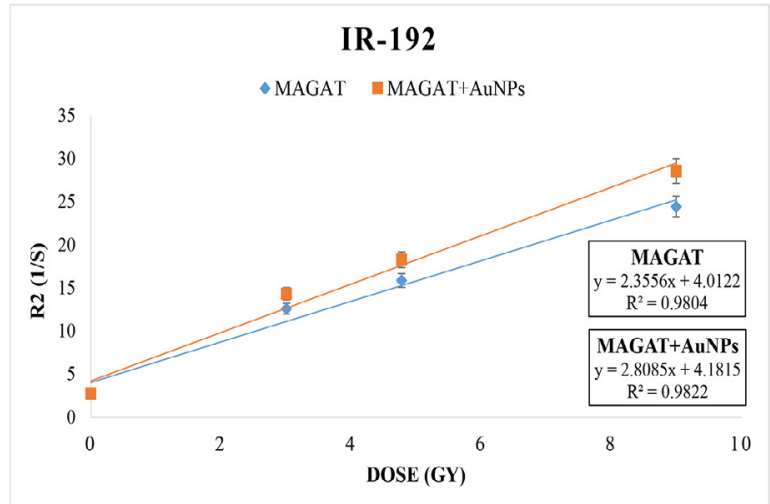

Figure 7: The R2-dose-response curve of AuNPs under Ir-192 internal radiotherapy compared to control group. Recorded error bars are mean standard deviations for three independent tests.

using MRI polymer gel dosimeter.

The curves presented in Figures 6 and 7 show a good correlation coefficient $\left(\mathrm{R}^{2}>0.98\right)$ of the R2- dose response for a gel containing AuNPs and a control group compared to other MAGAT gel studies [42, 47] in both incident energies. It is worth mentioning that, from each gel tube, eight T2-weighted MRI slices were prepared and the reported $\mathrm{R} 2 \mathrm{~s}$ is the result of averaging ROIs of 8 slices (in 3 independent tests). Therefore, this linear response in the dose range of $0-10 \mathrm{~Gy}$, in addition to demonstrating the good performance of the polymerization process within the applied dose range indicate the homogeneous distribution of AuNPs throughout the gelatin matrix. Although in cells, based on various factors, such as functionality and chemistry of the surface of NPs, this distribution is generally nonhomogeneous, and AuNPs can form small clusters or aggregates, but it is likely that these clusters/aggregates are distributed fairly uniform in the tumor tissue $[9,48]$.

The results of radiosensitivity evaluation demonstrated that the mean values of DEFs in the presence of AuNPs irradiated by Ir-192 and Co-60 sources were $15.32 \pm 0.31$ and $5.85 \%$ \pm 0.14 , respectively. The observed difference is 
Table 3: The values of the dose enhancement produced by $0.2 \mathrm{mM}$ concentration of AuNPs at various doses of the Ir-192 and Co-60 sources.

\begin{tabular}{cccc}
\multicolumn{2}{c}{ Co-60 } & \multicolumn{2}{c}{ Ir-192 } \\
\hline Dose (Gy) & DEF (mean+SD) & Dose (Gy) & DEF (mean+SD) \\
\hline 2.5 & $4.18 \% \pm 0.14$ & 3.01 & $13.84 \% \pm 0.54$ \\
\hline 5 & $5.32 \% \pm 0.10$ & 4.78 & $15.13 \% \pm 0.48$ \\
\hline 7.5 & $6.87 \% \pm 0.49$ & & $16.96 \% \pm 0.28$
\end{tabular}

due to the difference in the photoelectric cross section of AuNPs in the two studied energies [49]. The photoelectric absorption deals with the internal shell electrons and its probability increases when the incident photon energy is very close to (slightly greater than) the electron binding energy [50]. Given that the energy of gold K-edge $(80.7 \mathrm{KeV})$, up to this energy, the photoelectric effect predominates and then decreases rapidly. The photoelectric attenuation coefficient of gold in $380 \mathrm{KeV}$ energy is approximately $0.19 \mathrm{~cm}^{2} / \mathrm{g}$, which decreases to $1.03 \times 10^{-2} \mathrm{~cm}^{2} / \mathrm{g}$ for $1.25 \mathrm{MeV}$ [51]. On the other hand, the dominant process in the 1.25 MeV energy is the Compton effect, and this interaction occurs in the presence of free electrons. This interaction is independent of the atomic number and depends on the electron density. For most materials, exception hydrogen, the number of electron per gram $(\mathrm{e} / \mathrm{g})$ is almost the same. Consequently, the increase in doses in this energy and in the low concentrations of AuNPs is not justified based on e/g. In fact, owing to the dependence of the crosssection of the Compton scattering on the number of electrons in a specific thickness of the material, the important factor in the Compton attenuation is the number of electrons per cubic centimeter $\left(\mathrm{e} / \mathrm{cm}^{3}\right)$, not e/g [37]. By comparing e $/ \mathrm{cm}^{3}$ of gold with water $\left(4.66 \times 10^{24} \mathrm{e} /\right.$ $\mathrm{cm}^{3}$ for gold and $3.34 \times 10^{23} \mathrm{e} / \mathrm{cm}^{3}$ for water), the dose increase in $1.25 \mathrm{MeV}$ is completely in line with expectations.

In confirmation of the results, Khosravi et al., using MAGIC-f gel dosimetry, showed that 15 nm AuNPs were able to increase the absorbed dose about $15 \%$ under the irradiation of the Ir-192 source [52]. Ezati et al. also calculated the dose enhancement of about $55 \%$ produced by AuNPs in the diameter of $100 \mathrm{~nm}$ and in the concentration of $0.57 \mathrm{mM}$ under the irradiation of Ir-192 source [39]. Considering the higher concentration and larger dimensions of the NPs used in this study and the almost direct proportion of $\mathrm{DEF}$ with the concentration of NPs [53], the observed difference in the two studies is justifiable. In another gel dosimetry study, the dose enhancement of AuNPs, in a concentration of $0.1 \mathrm{mM}$ and irradiated with $250 \mathrm{kV}$ energy, was about 7 times higher than the result of the present study [54]. Due to the different size, concentration and energy used in this research compared to our study, and the high impact of each of these factors on DEF, it is obvious that the result of this study is also different from ours. Investigations on the radiosensitization of NPs in mega-voltage electron and photon beams show contradictory results. Rahman estimated $37 \%$ dose enhancement in the presence of $1 \mathrm{mM}$ of $2 \mathrm{~nm}$ AuNPs in $6 \mathrm{MeV}$ energy [35], while Roeske calculated the amount of DEF less than $1 \%$ for 1.9 $\mathrm{nm}$ AuNPs irradiated with 6 and $18 \mathrm{MV}$ beams [55]. In the study, the effect of backscatter has not been taken into account, which can result in the value of dose enhancement below the true value.

Notable thing is that in both of the studied energy in the present research, by increasing radiation dose, the DEF also increased. Actu- 
ally, by increasing the radiation dose, a number of free radicals produced from the water's radiolysis increase, as the amount of radicals produced by the NPs increases, which can react with more monomers and hence increase the polymerization process [56]. Thereby, DEF rises with increasing absorbed dose.

To quantitatively measure DEF, a polymer gel dosimeter was used. This dosimeter is equivalent to tissue in the interaction with the ionizing radiation, and can, accordingly, be used simultaneously as a phantom and dosimeter [43]. Moreover, the dosimeter is able to monitor the three-dimensional distribution of the delivered dose with high spatial resolution [46]. Besides, different chemicals such as NPs can be homogeneously incorporated into the dosimeter, while making it $[52,54,56]$.

From the normoxic-type gel dosimeters, MAGAT gel dosimeter was selected. As the results of this study indicate, this dosimeter due to its strong antioxidant (THPC), has a high sensitivity to absorbed dose changes with the dose-R2 sensitivity of 2.35 and 1.88 for Ir-192 and Co-60 sources, respectively (The reason for the lower dose sensitivity in the Co-60 source to Ir-192 is the lower dose rate of Ir-192 source compared with the Co-60 source [43]). Also, with $2 \%$ change in effective atomic number $\left(Z_{\text {eff }}\right)$ compared to water, $1 \%$ difference in radiological characteristics is very close to water $[57,58]$. Furthermore, in agreement with Lin et al. research [59], our results showed that MAGAT gel can be used as a powerful dosimeter to determine the absorbed dose distribution in the complex geometries of brachytherapy.

\section{Conclusion}

In summary, the current study explores the dosimetric feasibility of AuNPs-aided internal and external radiotherapy. We have applied the MAGAT gel dosimeter to quantitatively evaluate 3D dose distribution induced by AuNPs. Our results confirm the enhanced iridium-192 brachytherapy by AuNPs at a low concen- tration of $0.2 \mathrm{mM}$. In addition to the high $\mathrm{Z}$ and chemical stability of AuNP, the ability to synthesize it over a wide range of sizes, along with the capability of easy modification of the surface and flexible design, makes this nanoparticle very practical for multifunctionality medical applications. However, further proof-of-principle studies are needed for clinical utilization of this nanoparticle in diagnostics and radiation therapy.

\section{Acknowledgment}

Thanks to the Faculty of Medicine at Tehran University of Medical Sciences for funding this project (Grant No. 30862) and Bu-Ali Hospital, Research Center of Food and Drug Laboratory, and the Sina Hospital for facilitating the tests.

\section{Conflict of Interest}

\section{None}

\section{References}

1. Detappe A, Kunjachan S, Sancey L, Motto-Ros V, Biancur D, Drane $P$, et al. Advanced multimodal nanoparticles delay tumor progression with clinical radiation therapy. J Control Release. 2016;238:10313. doi: 10.1016/j.jconrel.2016.07.021. PubMed PMID: 27423325.

2. Moding EJ, Kastan MB, Kirsch DG. Strategies for optimizing the response of cancer and normal tissues to radiation. Nat Rev Drug Discov. 2013;12:526-42. doi: 10.1038/nrd4003. PubMed PMID: 23812271; PubMed Central PMCID: PMC3906736.

3. Satterlee $A B$, Yuan $H$, Huang L. A radio-theranostic nanoparticle with high specific drug loading for cancer therapy and imaging. J Control Release. 2015;217:170-82. doi: 10.1016/j.jconrel.2015.08.048. PubMed PMID: 26341695; PubMed Central PMCID: PMC4640695.

4. Butterworth KT, McMahon SJ, Currell FJ, Prise $\mathrm{KM}$. Physical basis and biological mechanisms of gold nanoparticle radiosensitization. Nanoscale. 2012;4:4830-8. doi: 10.1039/c2nr31227a. PubMed PMID: 22767423.

5. Hossain M, Su M. Nanoparticle location and material dependent dose enhancement in $\mathrm{X}$-ray radiation therapy. J Phys Chem C Nanomater Interfaces. 2012;116:23047-52. doi: 10.1021/jp306543q. PubMed PMID: 23393610; PubMed Central PMCID: 
PMC3563421.

6. Zhang XD, Wu D, Shen X, Chen J, Sun YM, Liu PX, et al. Size-dependent radiosensitization of PEG-coated gold nanoparticles for cancer radiation therapy. Biomaterials. 2012;33:6408-19. doi: 10.1016/j.biomaterials.2012.05.047. PubMed PMID: 22681980.

7. Byrne JD, Betancourt T, Brannon-Peppas L. Active targeting schemes for nanoparticle systems in cancer therapeutics. Adv Drug Deliv Rev. 2008;60:161526. doi: 10.1016/j.addr.2008.08.005. PubMed PMID: 18840489.

8. Detappe A, Tsiamas P, Ngwa W, Zygmanski P, Makrigiorgos $M$, Berbeco $R$. The effect of flattening filter free delivery on endothelial dose enhancement with gold nanoparticles. Med Phys. 2013;40:031706. doi: 10.1118/1.4791671. PubMed PMID: 23464301; PubMed Central PMCID: PMC3585757.

9. Cho SH, Jones BL, Krishnan S. The dosimetric feasibility of gold nanoparticle-aided radiation therapy (GNRT) via brachytherapy using low-energy gamma/x-ray sources. Phys Med Biol. 2009;54:4889-905. doi: 10.1088/0031-9155/54/16/004. PubMed PMID: 19636084; PubMed Central PMCID: PMC3064075.

10. Jones BL, Krishnan S, Cho SH. Estimation of microscopic dose enhancement factor around gold nanoparticles by Monte Carlo calculations. Med Phys. 2010;37:3809-16. doi: 10.1118/1.3455703. PubMed PMID: 20831089.

11. Berbeco RI, Ngwa W, Makrigiorgos GM. Localized dose enhancement to tumor blood vessel endothelial cells via megavoltage $X$-rays and targeted gold nanoparticles: new potential for external beam radiotherapy. Int J Radiat Oncol Biol Phys. 2011;81:2706. doi: 10.1016/j.ijrobp.2010.10.022. PubMed PMID: 21163591.

12. Ngwa W, Makrigiorgos GM, Berbeco RI. Gold nanoparticle-aided brachytherapy with vascular dose painting: estimation of dose enhancement to the tumor endothelial cell nucleus. Med Phys. 2012;39:392-8. doi: 10.1118/1.3671905. PubMed PMID: 22225308.

13. Lechtman E, Chattopadhyay N, Cai Z, Mashouf S, Reilly R, Pignol JP. Implications on clinical scenario of gold nanoparticle radiosensitization in regards to photon energy, nanoparticle size, concentration and location. Phys Med Biol. 2011;56:4631-47. doi: 10.1088/0031-9155/56/15/001. PubMed PMID: 21734337.

14. Leung MK, Chow JC, Chithrani BD, Lee MJ, Oms B, Jaffray DA. Irradiation of gold nanoparticles by $x$ rays: Monte Carlo simulation of dose enhancements and the spatial properties of the secondary electrons production. Med Phys. 2011;38:624-31. doi: 10.1118/1.3539623. PubMed PMID: 21452700.
15. Herold DM, Das IJ, Stobbe CC, Iyer RV, Chapman JD. Gold microspheres: a selective technique for producing biologically effective dose enhancement. Int J Radiat Biol. 2000;76:1357-64. PubMed PMID: 11057744.

16. Hainfeld JF, Slatkin DN, Smilowitz HM. The use of gold nanoparticles to enhance radiotherapy in mice. Phys Med Biol. 2004;49:N309-15. PubMed PMID: 15509078.

17. Chithrani BD, Ghazani AA, Chan WC. Determining the size and shape dependence of gold nanoparticle uptake into mammalian cells. Nano Lett. 2006;6:662-8. doi: 10.1021/nI0523960. PubMed PMID: 16608261.

18. Chithrani DB, Jelveh S, Jalali F, van Prooijen M, Allen $\mathrm{C}$, Bristow RG, et al. Gold nanoparticles as radiation sensitizers in cancer therapy. Radiat Res. 2010;173:719-28. doi: 10.1667/RR1984.1. PubMed PMID: 20518651.

19. Zhang XD, Wu D, Shen X, Chen J, Sun YM, Liu PX, et al. Size-dependent radiosensitization of PEG-coated gold nanoparticles for cancer radiation therapy. Biomaterials. 2012;33:6408-19. doi: 10.1016/j.biomaterials.2012.05.047. PubMed PMID: 22681980.

20. Fenart L, Casanova A, Dehouck B, Duhem C, Slupek $S$, Cecchelli $R$, et al. Evaluation of effect of charge and lipid coating on ability of $60-\mathrm{nm}$ nanoparticles to cross an in vitro model of the blood-brain barrier. $J$ Pharmacol Exp Ther. 1999;291:1017-22.

21. Leung MK, Chow JC, Chithrani BD, Lee MJ, Oms B, Jaffray DA. Irradiation of gold nanoparticles by $x$ rays: Monte Carlo simulation of dose enhancements and the spatial properties of the secondary electrons production. Med Phys. 2011;38:624-31. doi: 10.1118/1.3539623. PubMed PMID: 21452700.

22. Hauck TS, Ghazani AA, Chan WC. Assessing the effect of surface chemistry on gold nanorod uptake, toxicity, and gene expression in mammalian cells. Small. 2008;4:153-9. doi: 10.1002/smll.200700217. PubMed PMID: 18081130.

23. Alkilany AM, Nagaria PK, Hexel CR, Shaw TJ, Murphy CJ, Wyatt MD. Cellular uptake and cytotoxicity of gold nanorods: molecular origin of cytotoxicity and surface effects. Small. 2009;5:701-8. doi: 10.1002/ smll.200801546. PubMed PMID: 19226599.

24. Cho EC, Liu Y, Xia Y. A simple spectroscopic method for differentiating cellular uptakes of gold nanospheres and nanorods from their mixtures. Angew Chem Int Ed Engl. 2010;49:1976-80. doi: 10.1002/ anie.200906584. PubMed PMID: 20146292; PubMed Central PMCID: PMC3359148.

25. Au L, Zhang Q, Cobley CM, Gidding M, Schwartz $A G$, Chen J, et al. Quantifying the cellular uptake of 
antibody-conjugated Au nanocages by two-photon microscopy and inductively coupled plasma mass spectrometry. AcS nano. 2009;4:35-42.doi: 10.1021/ $\mathrm{nn} 901392 \mathrm{~m}$.

26. Mesbahi A, Jamali F, Garehaghaji N. Effect of photon beam energy, gold nanoparticle size and concentration on the dose enhancement in radiation therapy. Bioimpacts. 2013;3:29-35. doi: 10.5681/bi.2013.002. PubMed PMID: 23678467; PubMed Central PMCID: PMC3648909.

27. Alkilany AM, Murphy CJ. Toxicity and cellular uptake of gold nanoparticles: what we have learned so far? J Nanopart Res. 2010;12:2313-33. doi: 10.1007/ s11051-010-9911-8. PubMed PMID: 21170131; PubMed Central PMCID: PMC2988217.

28. Gatoo MA, Naseem S, Arfat MY, Dar AM, Qasim K, Zubair S. Physicochemical properties of nanomaterials: implication in associated toxic manifestations. Biomed Res Int. 2014;2014:498420. doi: 10.1155/2014/498420. PubMed PMID: 25165707; PubMed Central PMCID: PMC4140132.

29. Villiers $C$, Freitas $H$, Couderc R, Villiers MB, Marche $P$. Analysis of the toxicity of gold nano particles on the immune system: effect on dendritic cell functions. J Nanopart Res. 2010;12:55-60. doi: 10.1007/ s11051-009-9692-0. PubMed PMID: 21841911; PubMed Central PMCID: PMC3155055.

30. Pan Y, Leifert A, Ruau D, Neuss S, Bornemann J, Schmid G, et al. Gold nanoparticles of diameter 1.4 $\mathrm{nm}$ trigger necrosis by oxidative stress and mitochondrial damage. Small. 2009;5:2067-76. doi: 10.1002/ smll.200900466. PubMed PMID: 19642089.

31. Rahman WN, Bishara N, Ackerly T, He CF, Jackson $P$, Wong $C$, et al. Enhancement of radiation effects by gold nanoparticles for superficial radiation therapy. Nanomedicine. 2009;5:136-42. PubMed PMID: 19480049.

32. Kong T, Zeng J, Wang X, Yang X, Yang J, McQuarrie $S$, et al. Enhancement of radiation cytotoxicity in breast-cancer cells by localized attachment of gold nanoparticles. Small. 2008;4:1537-43. doi: 10.1002/ smll.200700794. PubMed PMID: 18712753.

33. Apanasevich V, Avramenko V, Lukyanov P, Lagureva A, Polkovnikova A, Lukyanenko K, et al. Enhance the absorption of gamma-ray energy inside the tumor using gold nanoparticles and iodine particles. Cancer and Oncology Research. 2014;2:17-20.

34. Amirrashedi M, Mostaar A, Haghgoo S, Gorji E, Jaberi $\mathrm{R}$, editors. Dose Enhancement in Radiotherapy by Novel Application Of Gadolinium Based MRI Contrast Agent Nanomagnetic Particles in Gel Dosimetry. Toronto: World Congress on Medical Physics and Biomedical Engineering; June 7-12, 2015.
35. Rahman WN, Wong CJ, Ackerly T, Yagi N, Geso M. Polymer gels impregnated with gold nanoparticles implemented for measurements of radiation dose enhancement in synchrotron and conventional radiotherapy type beams. Australas Phys Eng Sci Med. 2012;35:301-9. doi: 10.1007/s13246-012-0157-x. PubMed PMID: 22892958.

36. Maggiorella L, Barouch G, Devaux C, Pottier A, Deutsch E, Bourhis J, et al. Nanoscale radiotherapy with hafnium oxide nanoparticles. Future Oncol. 2012;8:1167-81. doi: 10.2217/fon.12.96. PubMed PMID: 23030491.

37. Sabbaghizadeh R, Shamsudin R, Deyhimihaghighi $\mathrm{N}$, Sedghi A. Enhancement of Dose Response and Nuclear Magnetic Resonance Image of PAGAT Polymer Gel Dosimeter by Adding Silver Nanoparticles. PLoS One. 2017;12:e0168737. doi: 10.1371/journal. pone.0168737. PubMed PMID: 28060829; PubMed Central PMCID: PMC5218462.

38. Deyhimihaghighi N, Noor NM, Soltani N, Jorfi R, Haghir ME, Adenan M, et al., editors. Contrast enhancement of magnetic resonance imaging (MRI) of polymer gel dosimeter by adding Platinum nanoparticles. Vol. 546. Journal of Physics: Conference Series; 2014.

39. Ezzati AO, Mahdavi SR, Anijdan HM. Size Effects of Gold and Iron Nanoparticles on Radiation Dose Enhancement in Brachytherapy and Teletherapy: A Monte Carlo Study. Iranian Journal of Medical Physics. 2014;11:253-9.

40. Kakade NR, Sharma SD. Dose enhancement in gold nanoparticle-aided radiotherapy for the therapeutic photon beams using Monte Carlo technique. J Cancer Res Ther. 2015;11:94-7. doi: 10.4103/09731482.147691. PubMed PMID: 25879344.

41. Bahreyni Toossi MT, Ghorbani M, Mehrpouyan M, Akbari F, Sobhkhiz Sabet L, Soleimani Meigooni A. A Monte Carlo study on tissue dose enhancement in brachytherapy: a comparison between gadolinium and gold nanoparticles. Australas Phys Eng Sci Med. 2012;35:177-85. doi: 10.1007/s13246-012-0143-3. PubMed PMID: 22700179.

42. Hurley C, Venning A, Baldock C. A study of a normoxic polymer gel dosimeter comprising methacrylic acid, gelatin and tetrakis (hydroxymethyl) phosphonium chloride (MAGAT). Appl Radiat Isot. 2005;63:443-56. doi: 10.1016/j.apradiso.2005.03.014. PubMed PMID: 16026995.

43. De Deene Y, Vergote K, Claeys C, De Wagter C. The fundamental radiation properties of normoxic polymer gel dosimeters: a comparison between a methacrylic acid based gel and acrylamide based gels. Phys Med Biol. 2006;51:653-73. doi: 10.1088/0031- 
9155/51/3/012. PubMed PMID: 16424587.

44. Fernandes JP, Pastorello BF, de Araujo DB, Baffa 0. Formaldehyde increases MAGIC gel dosimeter melting point and sensitivity. Phys Med Biol. 2008;53:N53-8. doi: 10.1088/0031-9155/53/4/N04. PubMed PMID: 18263941.

45. Geso M, Ackerly T, Brown S, Chua Z, He C, Wong $\mathrm{CJ}$, et al. Determination of dosimetric perturbations caused by aneurysm clip in stereotactic radiosurgery using gel phantoms and EBT-Gafchromic films. Med Phys. 2008;35:744-52. doi: 10.1118/1.2828200. PubMed PMID: 18383696.

46. Baldock C, De Deene Y, Doran S, Ibbott G, Jirasek A, Lepage $\mathrm{M}$, et al. Polymer gel dosimetry. Phys Med Biol. 2010;55:R1-63. doi: 10.1088/0031-9155/55/5/ R01. PubMed PMID: 20150687; PubMed Central PMCID: PMC3031873.

47. Chen D, Chung M-B, Shih T-C, Lian J, Chen Y. MAGAT Gel dosimetry validation in RapidArcTM treatment using Cone-beam CT. J Med Biol Eng In Press Accessed. 2012.

48. Alqathami M, Blencowe A, Geso M, Ibbott G. Quantitative 3D Determination of Radiosensitization by Bismuth-Based Nanoparticles. J Biomed Nanotechnol. 2016;12:464-71. PubMed PMID: 27280244.

49. Ngwa W, Kumar R, Sridhar S, Korideck H, Zygmanski P, Cormack RA, et al. Targeted radiotherapy with gold nanoparticles: current status and future perspectives. Nanomedicine (Lond). 2014;9:1063-82. doi: 10.2217/ nnm.14.55. PubMed PMID: 24978464; PubMed Central PMCID: PMC4143893.

50. Khan FM. The physics of radiation therapy. Vol. 3. Philadelphia: Lippincott Williams \& Wilkins; 2003.

51. Berger M, Hubbell J, Seltzer S, Chang J, Coursey J, Sukumar R, et al. XCOM: Photon cross sections database, 1998. NIST standard reference database. 1990;8.

52. Khosravi H, Hashemi B, Mahdavi S, Hejazi P. Effect of gold nanoparticles on prostate dose distribution under Ir-192 internal and 18 MV external radiotherapy procedures using gel dosimetry and monte carlo method. Journal of biomedical physics \& engineering. 2015;5:3.

53. Zhang DG, Feygelman V, Moros EG, Latifi K, Zhang GG. Monte Carlo study of radiation dose enhancement by gadolinium in megavoltage and high dose rate radiotherapy. PLOS One. 2014;9:e109389. doi: 10.1371/journal.pone.0109389. PubMed PMID: 25275550; PubMed Central PMCID: PMC4183586.

54. Marques T, Schwarcke M, Garrido C, Zucolot V, Baffa 0 , Nicolucci P, editors. Gel dosimetry analysis of gold nanoparticle application in kilovoltage radiation therapy. Journal of Physics: Conference Series; 2010: IOP Publishing.

55. Roeske JC, Nunez L, Hoggarth M, Labay E, Weichselbaum RR. Characterization of the theorectical radiation dose enhancement from nanoparticles. Technol Cancer Res Treat. 2007;6:395-401. doi: 10.1177/153303460700600504. PubMed PMID: 17877427.

56. Huang Y-R, Chang Y-J, Hsieh L-L, Liu M-H, Liu J-S, Chu $\mathrm{C}-\mathrm{H}$, et al. Dosimetry study of diagnostic $\mathrm{X}$-ray using doped iodide normoxic polymer gels. Radiation Physics and Chemistry. 2014;104:414-9.doi: 10.1016/j.radphyschem.2013.12.014.

57. Venning AJ, Nitschke KN, Keall PJ, Baldock C. Radiological properties of normoxic polymer gel dosimeters. Med Phys. 2005;32:1047-53. doi: 10.1118/1.1881812. PubMed PMID: 15895589.

58. Sellakumar P, Samuel EJJ, Supe SS. Water equivalence of polymer gel dosimeters. Radiation Physics and Chemistry. 2007;76:1108-15. Doi: 10.1016/j.radphyschem.2007.03.003.

59. Lin MH, Huang TC, Kao MJ, Wu J, Chen CL, Wu TH. Three-dimensional dosimetry in brachytherapy: A MAGAT study. Appl Radiat Isot. 2009;67:1432-7. doi: 10.1016/j.apradiso.2009.02.072. PubMed PMID: 19303785. 